\title{
ON THE EFFECTIVE SUBSTITUTION OF TURNINg BY PERIPHERAL MiLling
}

\author{
Miroslav Piska \& Stepan Kolomy
}
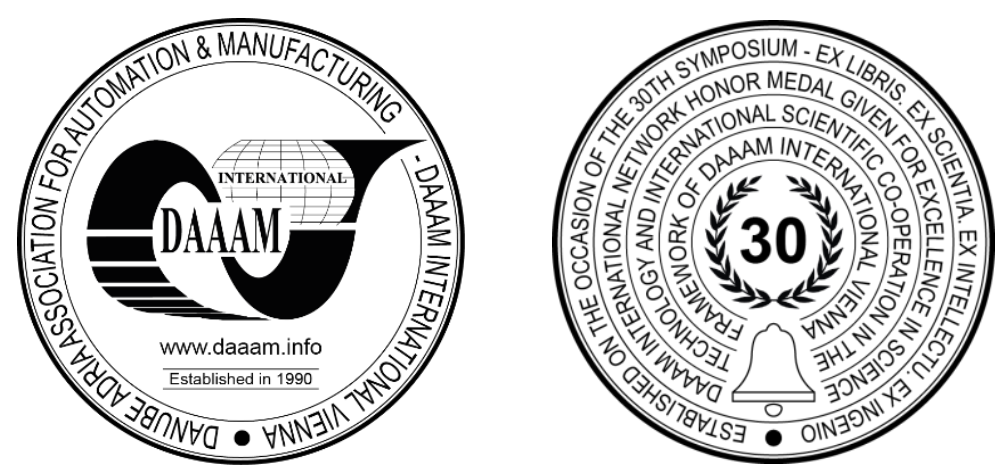

This Publication has to be referred as: Piska, M[iroslav] \& Kolomy, S[tepan] (2021). On the Effective Substitution of Turning by Perifheral Milling, Proceedings of the 32nd DAAAM International Symposium, pp.0016-0021, B. Katalinic (Ed.), Published by DAAAM International, ISBN 978-3-902734-33-4, ISSN 1726-9679, Vienna, Austria DOI: $10.2507 / 32$ nd.daaam.proceedings.003

\begin{abstract}
Turning operation seems to by prevailing for a production of rotational parts with standard demands on quality on machined surfaces. However, there are some applications that prevent effective use of the technology due to chip removal, entwining, clogging that prevents safe cooling of the turning tools and it ends frequently in a tool fracture or damage of the machined surface. Milling technology can suppress many of these problems, because the machining action is interrupted, chip is short and the cutting tool can machine even more surfaces in parallel. A difficult to machine welded assembly of stainless steel materials (the austenitic EN 1.4307 and the ferritic EN 1.4511) of profiled workpiece shape was selected for a substitution of the standard turning using several cutting tools by a milling and just one PVD coated monolithic cemented carbide tool. The series production of the part was selected and all quality parameters were first predicted, monitored and optimized. Finally, the economics of the production was assessed in terms of productivity and costs. All results confirmed a very stabilized production of good surface quality and long endurance of the milling tool (machined more then 30,000 pieces with one milling cutter).
\end{abstract}

Keywords: turning; milling; chip; loading;

\section{Introduction}

Modern technologies deal with many topics today how to enhance the productivity, to reduce the production cost, energy consumption, etc. Sometimes the researches investigate how to suppress vibrations when machining [1], the limits of the machine tools [2] and how to increase the cutting conditions [3]. There are advances in cutting materials [4], optimization of cutting geometry [5] or the principle of technology itself [6]. Modern technologies are focused on not only high speed or high feed machining of big parts, providing big material removals, but also to high quality of difficult to machine parts with small dimensions. The benefits of the productions stem frequently in several times higher added values, compared to the standard parts, and the production is more "green" and gentle to the environment. However, the orientation to the small dimensions reflects in special machinery, close tolerances and high demands on integrity of the produces surfaces. 
The selected part for the study was made as a welded assembly of two materials - the austenitic stainless steel 1.4307 and a ferritic stainless steel 1.4511 (X3CrNb17 [7]), and has a very special function in many applications. Anyway, this work deals only with machining the ferritic part only, which is difficult to machine due to big toughness and high tendency to production of built-up-edges, that result in many instabilities in the production (unacceptable dimensions, poor quality of surface, irregular wear of cutting tools, chipping, fractures etc. The first selected technology for production in the past was a classical turning using several cutting tools. However, the chip formation made the technology very risky. The second technology was a circular inner milling with the use of special indexable inserts. However, it failed also due to poor fastening of the inserts. So finally, a peripheral milling with a whole carbide tool was offered as a perspective alternative. The details of the technology undergo special know-how, so a limited information can be shared. Nevertheless, the solution was successful and used in daily practise and some information can be published today.

\section{Theoretical background, analysis of the technology}

The very basic information about the studied technology can be found in Fig. 1. The first problem is a machining of all surfaces in parallel in the up-milling circular interpolation. From the physical point of view, it is a loading of a beam by torque, shear and bending. The acting forces are generated from the material removal and wear mostly.

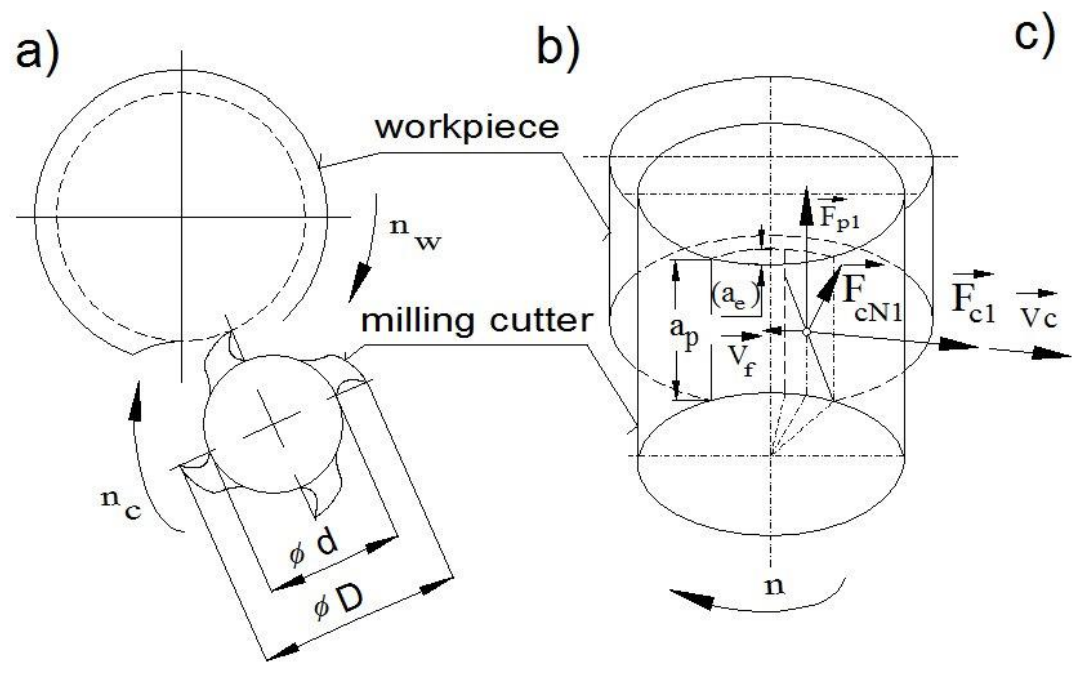

c)

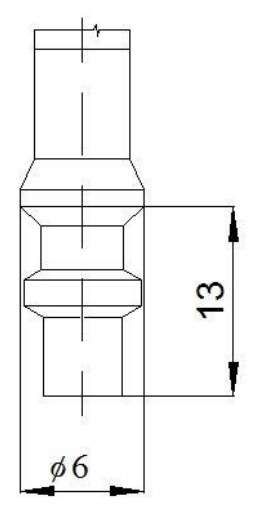

Fig. 1. Description of the machining: (a) principle of the peripheral milling,

(b) the expected force loading, (c) a piece of the part machined (simplified)

The sculptured design of the cutting tool or workpiece were complicated so an exact solution of the stresses and deformations by FEA might be more complicated than the works for simple face milling cutters in the past [8]. However, the expected deformations are needed for a CNC tool compensations [9], reflecting various rake geometry [10]. Some simplified solutions were assumed for the two solid cylinders corresponding to the outer diameter (maximal diameter of the beam) and inner diameter (upon the bottom of the flutes) as the first calculative iterations - Fig. 2.

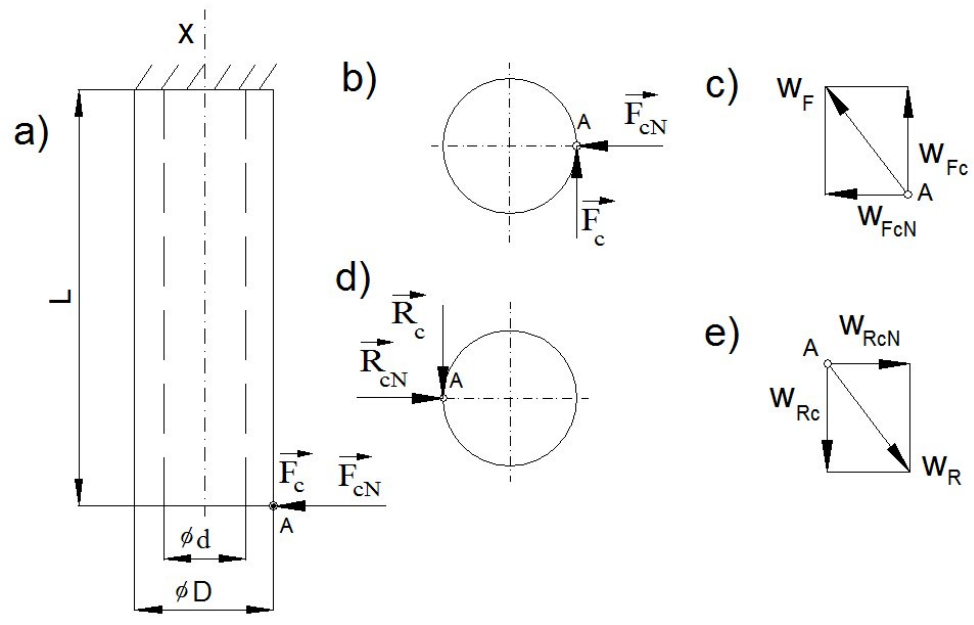

Fig. 2. Force loading and deformations at the machining: (a) a simplified model of the tool and the workpiece, $(b, c)$ the force loadings and deformations of the tool, $(\mathrm{d}, \mathrm{e})$ the force loadings and deformations of the workpiece 
The tool and workpiece deflections can be calculated analytically as deformations of the fixed beams, loaded by the force $\mathrm{F}$ (or its reactions R). The clamping end was regarded as fixed. In general, the beam is defined by the inertia moment $\mathrm{J}$, Young`s elasticity modulus E and the length L. The translational deformations of the cylindrical beams (either the milling tool or the workpiece) can be derived in general from the accumulated elastic energy (1):

$$
w_{f}=\frac{\partial W}{\partial F}=\frac{1}{E} \cdot \frac{M_{y}(x)}{J_{y}(x)} \cdot \frac{\partial M_{y}(x)}{\partial F} \cdot d x+\frac{\beta}{6} \cdot \int_{0}^{l} \frac{T_{z}(x)}{G_{(x)}} \cdot \frac{\partial T_{z}(x)}{\partial F} \cdot d x+\frac{1}{G} \cdot \int_{0}^{l} \frac{M_{k}(x)}{J_{p}(x)} \cdot \frac{\partial M_{k}(x)}{\partial F} d x
$$

and the angular deformations (2):

$$
\varphi_{M}=\frac{\partial W}{\partial M}=\frac{1}{E} \cdot \frac{M_{y}(x)}{J_{y}(x)} \cdot \frac{\partial M_{y}(x)}{\partial M} \cdot d x+\frac{\beta}{6} \cdot \int_{0}^{l} \frac{T_{z}(x)}{G_{(x)}} \cdot \frac{\partial T_{z}(x)}{\partial M} \cdot d x+\frac{1}{G} \cdot \int_{0}^{l} \frac{M_{k}(x)}{J_{p}(x)} \cdot \frac{\partial M_{k}(x)}{\partial M} d x
$$

where $\mathrm{W}$ is total stored elastic energy of the beam, M, Myx and Mk are bending and torque moments, Tz is a shear force (equel to force F), Jy and Jp are inertia and polar inertia moments, G is a shear modulus of elasticity, $\beta$ is a geometrical constant (1.66 for the cylindrical shape of a beam of L in length). The values of elasticity constants can be found at the material standards, but the values unfortunately vary. In general, the cemented carbides increase the rigidity of the beams approximately three times more than the steel materials, due to high values of $\mathrm{E}$ (about $6.86 .10^{11} \mathrm{~Pa}$ vs $2.17 .10^{11} \mathrm{~Pa}$ ). The cutting force for the teeth in a spiral was predicted according to the Fig. $1 \mathrm{~b}$ and the equation (3):

$$
F_{c}=\int_{\varphi_{1}}^{\varphi_{2}} d F_{c}=\int_{\varphi_{1}}^{\varphi_{2}} k_{c 1} \cdot d A_{D}=k_{c 1} \cdot \int_{\varphi_{1}}^{\varphi_{2}} \sqrt{R^{2}+\left(\frac{p_{s c r}}{2 \pi}\right)^{2}} \cdot f z^{1-m c} \cdot \sin \varphi^{1-m c} \cdot d \varphi=c_{o} \cdot \int_{\varphi_{1}}^{\varphi_{2}} \sin \varphi^{1-m c} \cdot d \varphi,
$$

where $A_{D}$ is the undeformed chip cross-section, $k_{c 1}$ is the specific cutting force acting on one cutting edge, $R$ is the radius of the tool, $\mathrm{p}_{\mathrm{scr}}$ is the pitch of the spiral, and $\phi_{1}, \phi_{2}$ the angle tool engagements, mc is the material coefficient and co is a multiplicative constant. The next problem is the predicted roughness of the machined surface - Fig. 3. The residual inequality Rzt depends on the diameters of the tool and workpiece, and the feed per teeth. So the angle $\omega$ should be computed according to the desired roughness as a programmed increment.

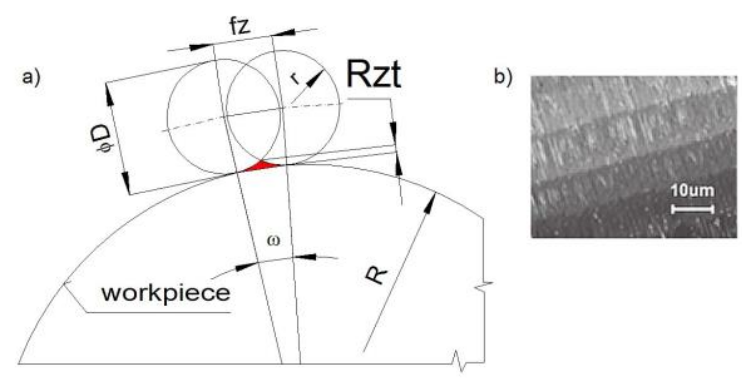

Fig. 3. A prediction of surface roughness as a function of tool geometry and cutting conditions (a), the real surface $(b)$.

A theoretical value of arithmetical mean deviation of the assessed profile Ra for the peripheral milling can be predicted approximately according to the equation (4) [11]:

$$
R a=\frac{1000 \cdot f_{z}^{2}}{18 \sqrt{3} \cdot r}
$$

\section{Experimental part}

The exact material composition and mechanical properties of the workpiece can be found in the Tables 1 and 2 . The diameter of the blank material was $6 \mathrm{~mm}$, the length $60 \mathrm{~mm}$, so it was easy to clamp it into a precise collet and chuck of a special milling machine (both developed just for the production). A special block of the ferritic stainless material with dimensions 50x100-120mm was also tested.

\begin{tabular}{|c|c|c|c|c|c|c|c|}
\hline $\mathbf{C}$ & Si & Mn & $\mathbf{P}$ & $\mathbf{S}$ & $\mathbf{C r}$ & $\mathbf{N b}$ & $\mathbf{F e}$ \\
\hline $\max 0.05$ & $\max . \quad 1.0$ & $\max . \quad 1.0$ & $\max .0 .04$ & $\max .0 .015$ & $16.0-18.0$ & $0.6-1.0$ & balance \\
\hline
\end{tabular}

Table 1. Chemical composition (in weight \%) of steel X3CrNb17 (1.4511): EN 10088-2-2005 


\begin{tabular}{|c|c|c|}
\hline Tensile strength Rm [MPa] & Proof strength $\mathbf{R}_{\mathbf{p 0 . 2}}$ [MPa] & Min. elongation at fracture A5 [\%] \\
\hline $420-620$ & $200-230$ & $20-23$ \\
\hline
\end{tabular}

Table 2. Mechanical properties of steel X3CrNb17 (1.4511)

The cutting tool of $6 \mathrm{~mm}$ in diameter, with four cutting flutes in helix $30^{\circ}$, was made of ultra fine grained $(0.5-0.9 \mu \mathrm{m})$ tungsten carbides ISO M20 and protected with extra smooth and uniform (Al,Ti)N coating (thickness 2.5-3.0 $\mu \mathrm{m}$, the PVD HIPIMS technology of CemeCon). The cutting conditions can be seen in the Table 3 . The machining routine consisted from two passes - roughing and finishing, following without any break. The run-ins and run-outs were made via the circular interpolation and six soft approaching points, so no tool marks after the machining could be detected from the entering and leaving of the cutter from the workpiece.

\begin{tabular}{|l|c|c|c|c|c|c|}
\hline Operation & $\begin{array}{c}\text { Average } \\
\text { adial depth } \\
\text { of cut ae } \\
{[\mathbf{m m}]}\end{array}$ & $\begin{array}{c}\text { Number of tool } \\
\text { rotations } \\
\mathbf{n}_{\mathbf{c}}\left[\mathbf{m i n}^{-1}\right]\end{array}$ & $\begin{array}{c}\text { Number of workpiece } \\
\text { rotations } \\
\mathbf{n}_{\mathbf{w}}\left[\mathbf{m i n}^{-\mathbf{1}}\right]\end{array}$ & $\begin{array}{c}\text { Average } \\
\text { cutting speed } \\
\mathbf{v}_{\mathbf{f}}[\mathbf{m m} / \mathbf{m i n}]\end{array}$ & $\begin{array}{c}\text { Feed speed } \\
\mathbf{v} \text { [mm/min] }\end{array}$ & $\begin{array}{c}\text { Axial } \\
\text { depth } \\
\text { of cut } \\
\mathbf{a}_{\mathbf{p}}[\mathbf{m m}]\end{array}$ \\
\hline Roughing & 0.9 & 7,000 & 400 & 132 & 125 & 13 \\
\hline Finishing & 0.1 & 7,000 & 400 & 132 & 80 & 13 \\
\hline
\end{tabular}

Cooling: Oil emulsion 12\% with EP additives, 6 outer nozzles, cooling pressure 20 bars, total cooling intensity 0.8 l/s.

Table 3. Cutting conditions for the milling operation

The cutting conditions were taken into consideration for the effective cutting rake and flank geometry. The abrasive mode of wear showed to be convenient and the machining exhibited a self-sharpening effect on the cutting flutes. Those synergetic effects resulted in low cutting forces, low deflections tool and workpiece and a stabilized machining.

The cutting forces were measured with the apparatus Kistler 9272, fully controlled with a PC. The data acquisition at the frequency $16 \mathrm{kHz}$ in every channel was set, the DynoWare v. 3 and Microsoft Excel 2021 were used for data processing - Fig. 4. The measurements were organized in two groups - the first one with machining of solid block of workpiece materials 50x100-120mm (to analyse the deflection of the tools) and then second one with the real workpieces).

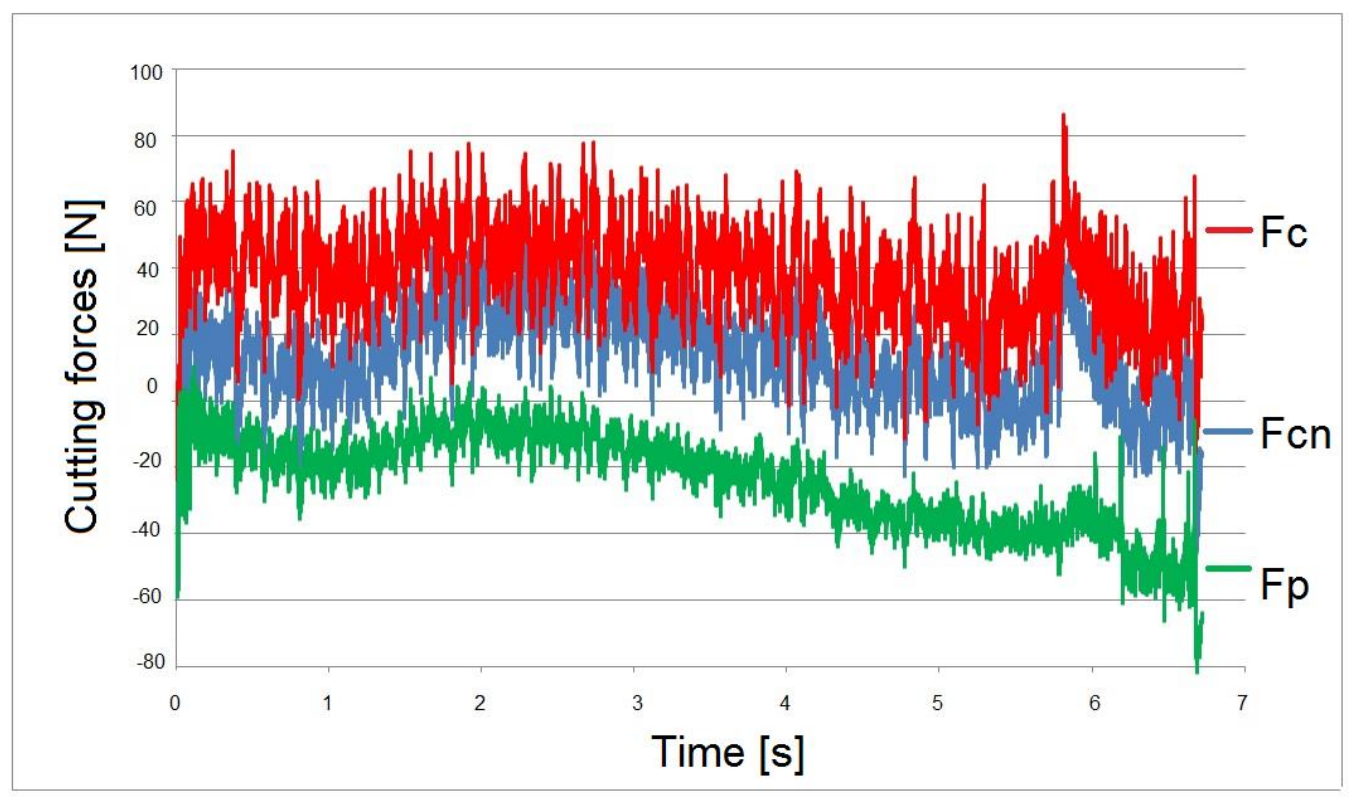

Fig. 4. An exhibition of cutting force measurement during one machining pass.

The predictions of the deformations and real measured values are plotted in the Fig. 5. The statistics is presented with the mean values of the deflections and the standard deviations (10 times repeated measurements with Alicona IF G5) 


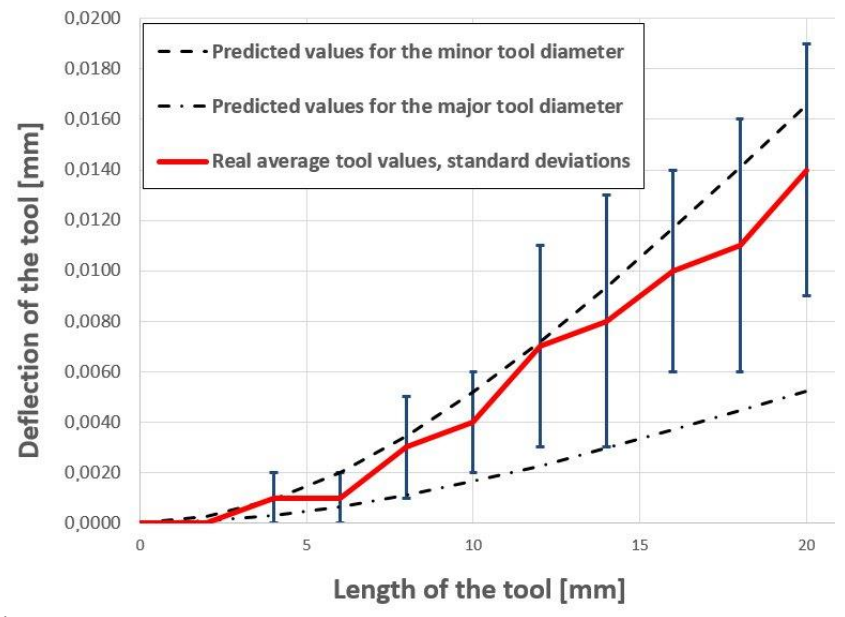

Fig. 5. Total deflections of the tool and workpiece when machining - predicted and measured values

The study of surface quality expressed by parameters Ra and Rz can be seen in Fig. 6. It can be said that the interval for lower feed speeds did not make good conditions for an effective chip production and many passes were not followed with a material removal as a chip. Moreover, the higher feed rates suppressed not only the built-up-edge production, but helped to acquire a better economy of the technology also.

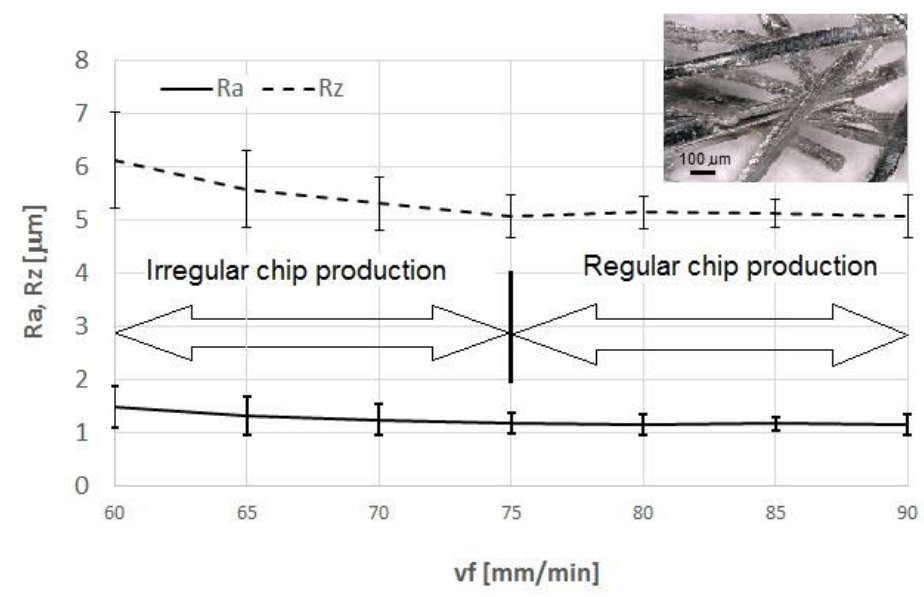

Fig. 6. The roughness parameters as a function of feed speed

A study devoted to the wear confirmed a very smooth abrasive mode of wear, stabilized in the whole tool life - Fig. 7. The cutting conditions altered in every cutting pass and the local places of the cutter underwent slightly different cutting conditions, but the endurance of the tool cutter was excellent and no big problem with chip removal has been watched.

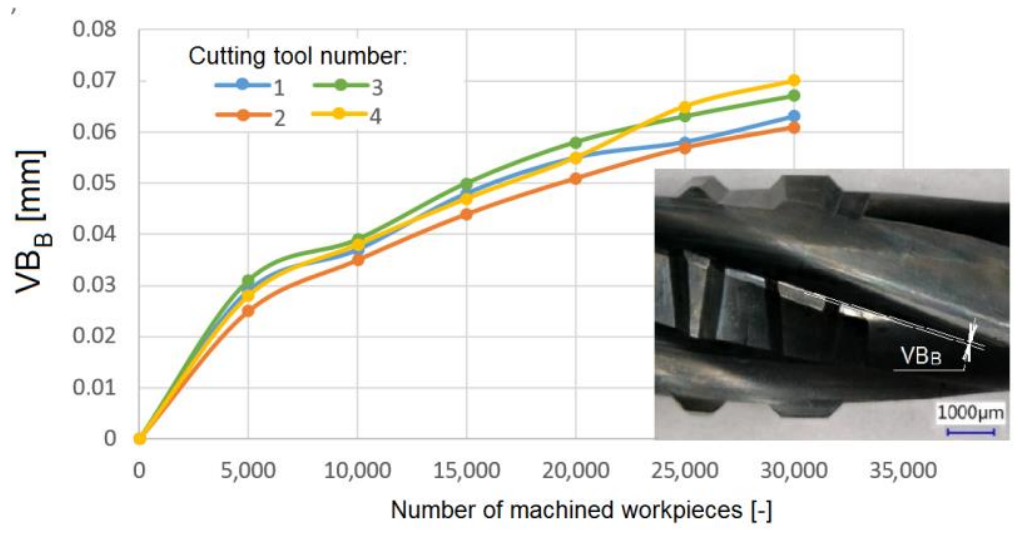

Fig. 7. Tool life as a function of finished machined workpieces

The cutting performance $-30,000$ pieces made by one milling cutter without any catastrophic failure was a very good record and there are some ways how to improve it more. 


\section{Conclusions}

The change of technology from turning to peripheral milling means a break point in the production technology and showed an efficient technology how to machine ferritic stainless steel. The substitution of the turning operation by milling was successful in all monitored parameters:

- the milling produced a very convenient chip formation and regular short chips,

- the milling cutter with a sharp geometry, protected with HIPIMS PVD technology provided excellent cutting performance even for the slim milling cutter and the overhang from the tool holder,

- the average cutting speed $132 \mathrm{~m} / \mathrm{min}$ and feed speed $90 \mathrm{~mm} / \mathrm{min}$ were verified as recommended values,

- the cutting conditions can be recommended for similar milling technologies of the material,

- the precision of the all machined dimensions was within IT10-11,

- the surface parameters Ra and Rz were below the allowed limits (2 $\square \mathrm{m}$ for Ra, and $6 \square \mathrm{m} \mathrm{for} \mathrm{Rz}$ ),

- the cooling of the milling was very effective and beneficial for the tool life,

- the outstanding cutting performance of the cutters was reached (30,000 parts per one milling tool),

- very low production costs were reached,

- the production has been running stabilized and smoothly so far for several months.

The new research and plans are devoted to a new tool design for 4-axis machining of the parts, taking into account the tool and workpiece deformations to reach the dimensional precision of IT 8-9.

\section{Acknowledgments}

These research works were kindly supported by the Brno University of Technology, FME, Specific research 2016, FSI S-16-3717 and the grant „Application of the New Surface Treatment Technologies in Metal Packaging Industry“, PID: FV40313, Ministry of Industry and Trade, The Czech Republic.

\section{References}

[1] Olt, J. \& Maksarov, V. (2016). Development of Chatter-Resistant System of Cutting Tool, Proceedings of the 26th DAAAM International Symposium, Katalinic, B. (Ed.), pp. 0223-0228, Published by DAAAM International, ISBN 978-3-902734-07-5, ISSN 1726-9679, Vienna, Austria DOI:10.2507/26th.daaam.proceedings.031

[2] Olt, J. \& Maksarov, V. (2016). Cutting process simulation on the basis of rheological properties of metals. Proceedings of the 26th International DAAAM Symposium, Katalinic, B. (Ed.), pp. 229-237. Published by DAAAM International, ISBN 978-3-902734-07-5, ISSN 1726-9679, Vienna, Austria. DOI:10.2507/26th.daaam.proceedings.032

[3] Kulenovic, M.; Begic, D. \& Cekic, A. (2007). Experimental investigation of carbon steel in high speed cutting. Annals of 18th DAAAM and Proceedings of the International DAAAM Symposium. Katalinic, B. (Ed.). pp. 411412, Published by DAAAM International, ISBN: 3-901509-58- 5. Vienna, Austria

[4] Hronek, O. \& Zetek, M. (2017) The influences of cutting edge radius on surface roughness when milling nickel alloy. Proceedings of the International DAAAM Symposium. pp. 1037-1043. Katalinic, (Ed.). ISSN 1726-9679, ISBN 978-3-902734-08-2. Vienna, Austria. DOI:10.2507/28th.daaam.proceedings. 144

[5] Belan, M. \& Michalik, P. (2012). The durability and wear of coated mills from HSS-PM in stainless steel cutting without cutting fluid. Proceedings of the 23rd International DAAAM Symposium, pp. 1031-1034. ISSN 2304-1382, ISBN 978-3-901509-91-9. Vienna, Austria

[6] Brenci, L.M., Cismaru, I., Cosereanu, C., Curtu, I., Lica, D. \& Fotin, A. (2009). The influence of the profiled milling parameters to the quality of the surface. Annals of the 19th DAAAM and Proceedings of the International DAAAM Symposium. Katalinic, B. (Ed.). pp. 413-414. ISSN 1726-9687, ISBN: 978-3-901509-69-8. Vienna, Austria

[7] ACERINOX. Https://www.acerinox.com/ [online]. [cit. 2021-09-25]. Available at: https://www.acerinox.com/opencms901/export/sites/acerinox/.content/galerias/galeria-descargas/galeria documentos-producto/ACX525-low.pdf

[8] Píška, M.; Zouhar, J. \& Polzer, A. (2009). Stress- strain analysis of end milling HSS cutters reflecting the wear process. CIRP Annual Meeting 2009. 2009-01-29/5. 3. Paris, France: CIRP, pp. 1-6.

[9] Píška, M.; Zouhar, J. \& Polzer, A. (2009). On the precise shoulder milling with an optimized 4- axis CNC machining. In Modern production technologies for the 21st century. Brno: CERM, 2009. pp. 43-47. ISBN: 978-80-214-39146.

[10] Zouhar, J. \& Píška, M. (2008). Modeling of the Orthogonal Machining Process using Cutting Tools with Different Geometry. In MATAR PRAHA 2008, Part 2: Testing, Technology. 1. Prague: SMT - Society for Machine Tools, pp. 81-86. ISBN: 978-80-904077-0-1.

[11] Davim, J. P. (2010). Surface Integrity in Machining. London: Springer. ISBN 978-1-84882-873-5. 